\title{
Explaining the Attitude towards Mathematics in Students on the Basis of Goal Adjustment Strategies and Metacognitive Beliefs
}

\author{
Sajjad Izadi1, Mahdieh Hadipour ${ }^{1}$, Naser Mohammadi Ahmadabadi2* \\ ${ }^{1}$ Payame Noor University, Taft, Iran \\ ${ }^{2}$ Department of Psychology and Educational Sciences, Payame Noor University, Tehran, Iran \\ Email: *Nasermohamadi89@yahoo.com
}

How to cite this paper: Izadi, S., Hadipour, M., \& Ahmadabadi, N. M. (2018). Explaining the Attitude towards Mathematics in Students on the Basis of Goal Adjustment Strategies and Metacognitive Beliefs. Creative Education, 9, 1042-1053.

https://doi.org/10.4236/ce.2018.97077

Received: May 2, 2018

Accepted: June 5, 2018

Published: June 8, 2018

Copyright $\odot 2018$ by authors and Scientific Research Publishing Inc. This work is licensed under the Creative Commons Attribution International License (CC BY 4.0).

http://creativecommons.org/licenses/by/4.0/

\begin{abstract}
The aim of this study was to Explaining Attitudes toward mathematics among Student on the basis of Goal adjustment strategies and metacognitive beliefs. In a Descriptive-correlational study, from among all students of various schools of Bafgh city, in 2016-2017, 310 students were selected using multistage cluster sampling method and using the margin of error Cochran. The participants completed the Goal adjustment strategies Scale, metacognitive beliefs Questionnaire, and Attitudes toward mathematics Questionnaire. Data analysis was performed using the Pearson correlation coefficient and multiple regression analysis (stepwise). The results showed significant negative relationship between Goal adjustment strategies with certain components of the attitude toward math. Also, the regression results showed that there is a significant-negative positive relationship between metacognitive strategies and some of the attitude to mathematics. These results also indicated that Goal adjustment strategies and metacognitive beliefs predictive for components of attitude to mathematics. From the findings of this study, it can be inferred that Goal adjustment strategies and metacognitive beliefs were important Factor of attitude to mathematics in students. Therefore, in educational programs for the mathematics among students, goal adjustment strategies and metacognitive beliefs require more attention.
\end{abstract}

\section{Keywords}

Attitudes toward Mathematics, Goal Adjustment Strategies, Metacognitive Beliefs

\section{Introduction}

Today, there are a multitude of issues in the educational system, among which 
the problem of educational failure in the lesson of mathematics leads to the loss of financial and human resources in the society in different ways; this issue imposes many adverse educational and mental consequences on students and their families (Zaki, 2011). The findings indicate that one of the most effective factors on the attitude of students is that they understand the application of mathematics in their real life. If the students consider the mathematics as a lesson that is not related to their real life, in this situation, they dislike mathematics and that is one of the greatest obstacles to the learning of this lesson (Khakbaz \& Moussapour, 2008). Numerous findings have shown that not only the educational achievement in mathematics is influenced by knowledge structures and the process of information processing, but it is also associated with motivational factors such as beliefs, attitudes, values and anxiety. Based on this, a close relationship was found between high level of motivation, positive attitude, low-level anxiety and performance in mathematics (Marchis, 2011). Therefore, emotion and feeling are important topics in the learning of mathematics that can create factors such as mathematics phobia and anxiety, joy of mathematics, self-confidence in mathematics and success or failure in mathematics (Rabab'h, 2015). Also, Aiken and Dreger (1961) showed that the attitude towards mathematics is the predictor of educational achievement in mathematics. Considering the importance of the attitude of students towards math lesson and its impact on their educational accomplishment, it is necessary to investigate factors that are associated with it. According to the results of conducted studies, one of the factors that can be related to students' attitudes towards mathematics is "goal adjustment strategies" (Midgley, 2014).

Conducted research in the field of self-regulation and adaptive human behavior emphasize essentially the importance of the role of goal attainment and its dependent processes and variables (Tsai et al. 2007). In reality, persistence in the goal path is followed by self-efficacy and optimism in reaching goals; but facing unattainable goals, accompanied with the experience of failure and difficulties in the goals path may cause the reduction of feeling of well-being, increase of depression, maintaining unrealistic tendencies and the increase of psychological pressure (Cook, Casillas, Robbins, \& Dougherty, 2005). Therefore, in order to regulate these negative effects, goal adjustment, or in other words, the ability of a person to knock out the unattainable goal or move towards a new goal and change the previous one, helps this person to prevent the accumulation of fail-based experiences (Vollrath et al., 1994). Furthermore, knocking out the unachievable goal helps the person to redefine a new goal and he/she might realize that the previous goal was not necessary and essential for the sense of satisfaction in life, in this way, this person can adapt him/herself with the inability to achieve the goal or set a new appropriate goal (Moshtaghi, 2012). It is believed that individuals, after deciding to abandon the unachievable goals, they seek for a new goal and have the tendency to shift their intellectual capacity to the new accepted target and this fact helps to relieve the previous failure, reduce the 
stress and anxiety and improve the educational achievement (Elliot, McGregor, \& Gable, 1999). The research results regarding the educational achievement and goal adjustment are contradictory. Some studies have shown that goal adjustment helps to have educational achievement, whereas some other studies do no cite a significant relationship between educational achievement and goal adjustment (Kiliç-Çakmak, 2010). But few studies have been conducted on the relationship between the attitude towards mathematics and goal adjustment.

Moreover, the importance of cognition and metacognition and their relationship with the educational progress in mathematics and the attitude towards mathematics is inevitable. The metacognition can be defined as the learning process of how to learn. More specially, the metacognition can be considered as the manner of controlling the thought and learning process and applying it in practice. In other words, the main definition of metacognition is "cognition about cognition". It is the ability of our consciousness of what we know and what we do not know. The concept of "metacognition" means the awareness of one's learning process or how to learn (McCormick, Dimmitt, \& Sullivan, 2013). By using metacognitive strategies, the learner considers how to deal with a subject, which approach to adopt, check out his/her error while progress, conceptualize again the attitude towards the subject and reflect it in the result. Metacognitive beliefs are in fact the approaches that help learners to realize whether or not they have understood what they have read or done and which techniques can help them understand the subject. While performing sophisticated activities, these skills help learners refer to what, how, when, where and why they are learning. In terms of behavior, they are thus considered as active contributors in learning process. These beliefs and strategies are in fact measures to control cognitive strategies (organizing, repetition and review, developing or linking subjects) and conducting them. Major metacognitive strategies can be classified into three categories of planning, revising and regulation (Corno \& Andersson, 2015). With the help of cognitive strategies, skilled learners achieve progress and through the metacognitive strategies, they supervise cognitive strategies in order to enhance their progress (Ahmaditahour et al., 2011). However, research evidence in the field of the relationship between metacognitive beliefs and educational achievement is not as coherent. The findings of a number of studies indicate that metacognitive strategies have a positive relationship with educational progress in mathematics and the attitude towards math lesson (Liem, Lau, \& Nie, 2008). But some other studies have shown that this relationship is not significant (Miller \& Geraci, 2011).

In sum, according to the aforementioned descriptions, it becomes clear that goal adjustment and metacognitive beliefs can be associated with the attitude towards mathematics in students. Nevertheless, further research is required in this domain. Moreover, given the importance of mathematics and the attitude of students towards this lesson, which is an important factor in their progress in mathematics and also the remarkable educational failure and deterioration of 
students in math lesson, it is necessary to investigate the effective factors on the attitude of students towards mathematics. Accordingly, the present study has been conducted with the purpose of answering the question of whether or not it is possible to explain the attitude of students towards mathematics based on goal adjustment strategies and metacognitive beliefs.

\section{Materials and Methods}

The present study is descriptive-correlational. The statistical population of this research consists of all students of the first year of secondary school $(\mathrm{N}=1500)$ in the city of Bafgh in Iran, during the academic year 2016-2017. The study sample consists of 310 students, selected by Cochran's formula, with the error level of 0.05 and using multi-stage cluster sampling method. Firstly, 6 secondary schools were randomly selected. Then, 50 to 55 students were selected randomly from the students of the first, second and third years. In the present research, several tools were used to assess the variables. In what follows, we describe them.

For measuring the attitude of students towards mathematics, the Aiken Attitude to Mathematics Scales (1961) was used. This questionnaire of attitude towards mathematics is designed in Likert scale and with 24 items. For each item, there are five options from "I strongly agree" to "I strongly disagree" with the scores from 5 to 1 . The minimum score of this questionnaire is 24 and the maximum score can be 120. A high score in this questionnaire shows a positive attitude towards mathematics and a low score shows a negative attitude. The scores of 5 to 1 are related to the options of "I strongly agree", "I agree", "I neither agree, nor disagree', "I disagree" and "I strongly disagree", respectively. In some items, the question is reversed, the scoring method is thus also reversed, that is, I strongly disagree $=5$, I disagree $=4$, I neither agree, nor disagree $=3$, I agree $=2$ and I strongly agree $=1$. In the study of Farahani and Keramati (2002), exploratory factor analysis was used for determining the validity of the questionnaire. The fitness of model for the variables (components) of attitude towards mathematics for the validity, based on the indicators of RMSEA, NFI, CFI and GFI was measured and these indicators were respectively $0.06,0.89,0.90$ and 0.89. For determining the reliability of the questionnaire, Cronbach's alpha coefficient was used; this coefficient was respectively equal to $0.88,0.87,0.89$ and 0.87 for the subscales of enjoyment, motivation; giving importance and phobia and anxiety.

Goal Adjustment Scale was created by Wrosch et al. (2011) and it includes 10 questions that are scored on a five-point Likert scale from I strongly disagree (1) to I strongly agree (5). This scale contains two subscales of goal disengagement in the form of 4 questions (Items 1, 3, 6 and 8) and goal reengagement in the form of 6 questions (Items 2, 4, 5 and 7). The subscale of goal disengagement emphasizes the perceived difficulty by the individual for reducing his/her efforts and knocking out his/her current and considered goals, and the subscale of goal reengagement emphasizes the ability of an individual to redefine goals and pur- 
sue another target in case of facing restrictions in attaining his/her current goal. Verash et al. estimated the reliability of this questionnaire between 0.76 and 0.84 . Despite what was mentioned regarding the validity of goal adjustment scale, for applying it in the Iranian society, the psychometric properties of said scale were investigated in the study of Bahrami (2012). The validity of this scale was assessed through face validity. For this purpose, before implementation, the Persian translation of goal adjustment scale was put at disposal of two of faculty members of the department of psychology, faculty of educational sciences and psychology in Ferdowsi University of Mashhad, and both of them agreed on the appropriateness of questions. Also, In order to assess the validity of the Persian translation of this scale, the Cronbach's alpha coefficient, which emphasizes the internal consistency, was used. The Cronbach's alpha coefficient for the overall score of the scale was obtained 0.72 that indicates an acceptable validity of this questionnaire.

Metacognitive strategies questionnaire of Pintrich \& De Groot (1990) has been designed in Likert scale with 8 items. For each item, there exist five options, from I strongly agree to I strongly disagree and their scores vary from 5 to 1 . The minimum score obtained from this questionnaire is 8 and the maximum score is 40. This questionnaire contains three components of planning, control and supervision, and arrangement. The items 1 and 2 are related to the component of planning, the items 3, 4, 5 and 6 are related to the component of control and supervision and the items 7 and 7 are associated with the component of arrangement.. The fitness of model for the variables (components) of cognitive strategies for the validity, based on the indicators of RMSEA, NFI, CFI and GFI was measured and these indicators were obtained $0.06,0.89,0.90$ and 0.89 , respectively. For determining the reliability of the questionnaire, the Cronbach's alpha coefficient was used. This coefficient was equal to $0.70,0.69$ and 0.71 for the three subscales of planning, supervision and control, and arrangement, respectively. The questionnaire makers have reported that the reliability of this questionnaire was optimal and its reliability coefficient in this study was obtained 0.78 using Cronbach's alpha method. After obtaining the necessary permissions and coordinating with the educational department of the district and also the schools in question, the researcher referred to the schools and after explaining the instruction about questionnaire completion, the questionnaires were distributed to the students, the completion time was 30 minutes and the period of data gathering lasted two months. The data were analyzed using multiple regression model with step by step method in order to identify variables contributing to the prediction of the attitude towards mathematics.

\section{Findings}

In Table 1, the mean and standard deviation of the variables of goal adjustment strategies and metacognitive beliefs as predictor variables, attitude towards mathematics as the criterion variable and also Pearson's correlation coefficients 
between goal adjustment strategies, metacognitive beliefs and the attitude towards mathematics are shown. The data of Table 1 show that there is a negative and significant relationship between goal adjustment strategies and some components of attitude towards mathematics; these relationships are: the relationship of goal disengagement with giving importance and phobia and anxiety and the relationship of reengagement strategy with motivation and giving importance.

Other relationships between goal adjustment strategies and the attitude towards mathematics are not statistically significant. Also, the results of the table below show that there is a positive and significant relationship between metacognitive strategies and some components of attitude towards mathematics. Their relationships were: The positive relationship of planning with enjoyment and motivation and the negative relationship of planning with phobia and anxiety, the positive relationship of supervision and control with motivation and giving importance and the positive relationship of arrangement with phobia and anxiety.

For investigating the role of goal adjustment strategies and metacognitive beliefs on the components of attitude towards mathematics, multiple regression analysis with step by step method was used. For this purpose, in all equations, the presumptions of using regression model were firstly examined using Durbin-Watson test to investigate the independence of errors and collinearity with indices of tolerance coefficient and variance inflation factor. The Table 2 shows the results of Durbin-Watson test and collinearity indices. According to the data of Table 2 , it can be said that the numerical values of Durbin-Watson test indicate the independence of the errors for the examined variables and the indicators of collinearity of tolerance coefficients and variance inflation factor (VIF) show that there is no collinearity between predictor variables and the obtained results from regressions model can be valid. Other regression characteristics of investigating the role of goal adjustment strategies and metacognitive beliefs in attitude towards mathematics can be seen in Table 3.

Table 1. Mean, standard deviation and correlation of goal adjustment strategies, metacognitive beliefs and the components of the attitude to mathematics $(\mathrm{n}=310)$.

\begin{tabular}{|c|c|c|c|c|c|c|}
\hline Variables & Mean & Standard deviation & Enjoyment & Motivation & Giving importance & Phobia and anxiety \\
\hline Disengagement & 8.96 & 3.03 & 0.002 & -0.10 & $* *-0.17$ & $*-0.15$ \\
\hline Planning & 3.83 & 1.43 & ${ }^{*} 0.20$ & ${ }^{*} 0.17$ & 0.10 & $*-0.13$ \\
\hline Supervision and control & 9.45 & 1.80 & 0.04 & ${ }^{* *} 0.16$ & ${ }^{* *} 0.16$ & 0.02 \\
\hline Arrangement & 7.80 & 1.16 & 0.01 & 0.08 & -0.04 & ${ }^{*} 0.16$ \\
\hline Enjoyment & 16.34 & 2.72 & & & & \\
\hline Motivation & 17.35 & 2.79 & & & & \\
\hline Giving importance & 15.57 & 2.74 & & & & \\
\hline
\end{tabular}

${ }^{*} p<0.05 ;{ }^{* *} p<0.01$. 
Table 2. Numerical values of Durbin-Watson test, tolerance coefficient and variance inflation factor for investigating the independence of errors and collinearity presumption.

\begin{tabular}{|c|c|c|c|c|}
\hline Criterion variable & Predictor source & Durbin-Watson test & Tolerance coefficient & VID indices \\
\hline \multirow[t]{2}{*}{ Enjoyment } & Planning & 1.73 & 1.00 & 1.00 \\
\hline & Planning & & 0.96 & 1.04 \\
\hline \multirow[t]{3}{*}{ Motivation } & Goal reengagement & 1.84 & 0.98 & 1.01 \\
\hline & Supervision and control & & 0.97 & 1.02 \\
\hline & Goal reengagement & & 0.91 & 1.10 \\
\hline \multirow[t]{3}{*}{ Giving importance } & Supervision and control & 1.76 & 1.00 & 1.00 \\
\hline & Goal disengagement & & 0.91 & 1.10 \\
\hline & Regulating & & 0.99 & 1.00 \\
\hline \multirow[t]{2}{*}{ Phobia and anxiety } & Goal disengagement & 2.07 & 0.98 & 1.02 \\
\hline & Planning & & 0.98 & 1.01 \\
\hline
\end{tabular}

Table 3. Statistical features of step by step regression of goal adjustment strategies and metacognitive beliefs on the components of attitude towards mathematics.

\begin{tabular}{|c|c|c|c|c|c|c|c|c|c|}
\hline Criterion variable & Step & Predictor variable & $\mathrm{R}$ & $\mathrm{R}^{2}$ & Df & $\mathrm{F}$ & B & Beta & $\mathrm{T}$ \\
\hline \multirow[t]{2}{*}{ Enjoyment } & First & Planning & 0.20 & 0.04 & 1.278 & $* * * 12.61$ & 0.39 & 0.20 & $* * * 3.55$ \\
\hline & First & Planning & 0.17 & 0.03 & 1.278 & $* * 8.83$ & 0.26 & 0.13 & $\star 2.27$ \\
\hline \multirow[t]{3}{*}{ Motivation } & Second & Goal reengagement & 0.22 & 0.05 & 1.277 & $* * * 7.19$ & -0.08 & -0.14 & $* *-2.46$ \\
\hline & Third & Supervision and control & 0.26 & 0.07 & 1.276 & $* * * 6.87$ & 0.22 & 0.14 & ${ }^{* *} 0.44$ \\
\hline & First & Goal reengagement & 0.19 & 0.04 & 1.278 & $* * * 10.63$ & -0.09 & -0.15 & ${ }^{* *}-2.58$ \\
\hline \multirow[t]{3}{*}{ Giving importance } & Second & Supervision and control & 0.25 & 0.06 & 1.277 & $* * * 9.28$ & 0.25 & 0.17 & $\star * * 2.85$ \\
\hline & Third & Goal disengagement & 0.28 & 0.08 & 1.276 & $\star * \star 7.77$ & -0.11 & -0.13 & $\star-2.12$ \\
\hline & First & Arrangement & 0.16 & 0.03 & 1.278 & $* * 7.58$ & 0.31 & 0.14 & $* * 2.49$ \\
\hline \multirow[t]{2}{*}{ Phobia and anxiety } & Second & Goal disengagement & 0.22 & 0.05 & 1.277 & $\star * * 6.73$ & 0.13 & 0.16 & $* * *-2.72$ \\
\hline & Third & Planning & 0.26 & 0.07 & 1.276 & $* * * 6.66$ & 0.25 & 0.14 & $* *-2.50$ \\
\hline
\end{tabular}

${ }^{*} p<0.05 ;{ }^{* *} p<0.01 ;{ }^{* *} p<0.001$.

Table 3 shows the statistical features of step by step regression related to goal adjustment strategies, metacognitive beliefs on the components of the attitude towards mathematic in students. The results of this table indicate that planning strategy has predicted the component of enjoyment and attitude towards mathematics by explaining $0.04 \%$ of its variance. Planning strategies, goal reengagement, and supervision and control have predicted the components of motivation and attitude towards mathematics with $0.03 \%, 0.05 \%$ and $0.07 \%$ of variance, respectively. The strategies of goal reengagement, supervision and control and goal disengagement have predicted the components of giving importance and attitude towards mathematics by explaining $0.04 \%, 0.06 \%$ and $0.08 \%$ of variance, respectively. Also, the components of arrangement, goal disengagement and planning have predicted the components of phobia and anxiety and attitude towards mathematics by explaining respectively $0.03 \%, 0.05 \%$ and 0.07 of variance. 
In general, it can be said that goal adjustment strategies and metacognitive beliefs are significant predictors for students' attitude towards mathematics.

\section{Discussion}

This study was conducted with the purpose of explaining the attitude towards mathematics in students based on goal adjustment strategies and metacognitive beliefs of students. The obtained results showed that goal adjustment strategies and metacognitive beliefs can explain students' attitude towards mathematics and are significant predictors for the components of the attitude towards mathematics in students. These results are in line with the study results of Razavieh et al. (2005), Fouladchang (2007), Weissi \& Talepasand (2014), Wigfield \& Cambria (2010) and Ashcraft \& Kirk (2001) based on the relationship of goal adjustment strategies and metacognitive beliefs with the attitude of students towards mathematics and their educational progress in this domain.

In the explanation of the relationship between goal adjustment strategies and attitude towards mathematics, it can be argued that goal adjustment is the intention or motivation that the learner pursues beyond the effort in the situation of progress. The importance of this structure is due to its different motivational, cognitive, behavioral and emotional effects on educational performance and progress (Rabbani \& Youssefi, 2014). The goal adjustment in educational situations explains the motivation of individuals for studying and for this reason, it influences the tendencies, actions and responses of the learner in different learning situations. It is merely a stimulus for individuals to learn a special assignment in special circumstances, which is the basis of individual differences in educational situations. Some students show reactions accompanied by enjoy and eagerness about their school assignments and some others show refusal and reluctance (Dadvand, 2013).

Numerous findings have shown that educational achievement especially in the lesson of mathematics is associated with motivational factors such as beliefs, attitudes, values and anxiety. Therefore, feeling and emotion in the learning process of mathematics are very important subjects and can create factors like mathematics anxiety and phobia, the enjoyment of mathematics, self-confidence and success or failure in mathematics (Yar Mohammadi Vassel et al., 2014). Also, some students cannot have a positive attitude towards mathematics courses because of having some characteristics such as external motivation, comparing themselves with other students and having mathematics phobia and anxiety. Their targets are: competing with other students, attaining success with a low effort and this leads to less progress and negative attitude towards mathematics (Barzegar Bafrooei et al., 2014).

Accordingly, goal orientation and goal setting in students can help them have a sense of belonging to mathematics, enjoy from activities that require the use of mathematical knowledge, consider it as an interesting and worthful lesson and increase their concentration in order to achieve their goals. Whereas, if the stu- 
dent is not aware of his/her goal orientation, he/she cannot have enough motivation for progress in mathematics and will have a negative attitude towards math lesson (Razavieh et al., 2005). Also, in the explanation of the relationship between metacognitive beliefs and attitude towards math lesson, it can be said that today, the metacognition is considered as one of the most important factors for explaining students' educational progress and its impact is remarkable in doing different school assignments by students especially in math lessons.

Several studies have shown that the type of attitude of students is related to metacognitive beliefs (Martinez, 2006). An individual with a relatively good metacognitive consciousness knows to what extent he/she has perceived different math lessons and knows also which methods should be used. Such an individual has thus a positive attitude towards math lesson (Kuhn, 2006). In this regard, Billstein et al. (2015) believe that the deficiency in metacognitive skills is one of the important factors of learners' failure in doing mathematics assignments and creates a negative attitude towards math lesson. Montague, Warger \& Morgan (2000) emphasize specially the attitude towards math lesson and believe that if the teacher is not acquainted with new methods of mathematical information processing in students, their intellectual and cognitive processes and their attitudes and beliefs, he/she won't be able to teach effectively the lesson of mathematics. Hence, by teaching metacognitive beliefs, the attitude of students towards math lesson becomes positive and they will be more conscious of their performance. This is a current process that includes prediction, action and reflection. By this prediction before action, the individual receives feedback and becomes aware of obstacles, difficulties, interruptions and different harassments. This individual has planning regarding the use of time and education, carrying out assignments and projects, and career and success in the society and has often a high level of motivation for educational progress (Delavar et al., 2015). Thus, if the students are capable of applying metacognitive strategies for an effective learning of mathematics, they will become smart learners who will achieve higher levels of problems solving skills during their learning process. They attain success in this field and believe the fact that they have the necessary skills and abilities to carry out math assignments, they spend thus more time doing these assignments and finally, they will achieve better results and will have a positive attitude towards the learning process of the lesson of mathematics (Rostami \& Aliabadi, 2014).

Furthermore, students with metacognitive skills facilitate their learning process in math lesson by applying the strategy of supervision and control, and they influence their intrinsic motivation. They will thus gain more educational success by correcting mistakes and increasing the speed of learning and problems solving, and subsequently, they will have a higher level of motivation and a more positive attitude towards mathematics (Price, 2016). Also, the students who apply the strategies of arrangement, they can thus re-examine and review their failures and the active learning process will be improved in them. These students have a high level of motivation for educational progress; they seek to 
gain competencies, mastery and arrangement. In their learning process of mathematics, they apply the strategies of expansion and arrangement in a sophisticated and profound manner, they enjoy more the challenges and self-orientation and consequently, they will gain a more positive attitude towards math lesson (Elliot \& McGregor, 2001).

\section{Conclusion}

In general, the results of this study showed that goal adjustment strategies and metacognitive beliefs can predict the attitude of students towards mathematics. According to these results, it can be argued that these findings have important educational implications in psychology and educational sciences. Because as previously mentioned, the attitude towards mathematics has a crucial effect on various personal and societal spheres and also on the educational futures of students. Knowing the factors and variables related to it is thus of utmost importance. Despite the important results that are obtained from this study, but like other studies, there are some limitations in the present study. The most important limitation of this study is its dependence on to the students of one geographical region (The city of Bafgh); it is thus not possible to generalize the results of this research to other individuals and students. It is recommended that the same study be conducted in other groups and individuals and the results be investigated.

\section{Acknowledgements}

At the end of this study, we thank and appreciate the authorities of the educational department of the city of Bafgh and all teachers and student who participated in this study.

\section{References}

Ahmaditahour, M., Rabiei, M., Karimi, L., \& Shomousi, N. (2011). Effectiveness Cognitive Symptoms of Body Dysmorphic Disorder (Case Study). Journal of Sabzevar University of Medical Sciences, 18, 26-32.

Aiken Jr., L. R., \& Dreger, R. M. (1961). The Effect of Attitudes on Performance in Mathematics. Journal of Educational Psychology, 52, 19-24. https://doi.org/10.1037/h0041309

Ashcraft, M. H., \& Kirk, E. P. (2001). The Relationships among Working Memory, Math Anxiety, and Performance. Journal of Experimental Psychology: General, 130, 224-237. https://doi.org/10.1037/0096-3445.130.2.224

Bahrami, Z. (2012). Investigation of the Mediating Role of Emotional Cognitive Ordering Strategies and Goal Adjustment in the Relationship between Personality Characteristics and Quality of Life in Cancer Patients. Master's Thesis, Faculty of Educational Sciences and Psychology, Ferdowsi University of Mashhad.

Barzegar Bafrooei, K., Barzegar Bafrooei, M., \& Molayi Bahrami, Y. (2014). The Role of Goal Orientation and Metacognitive Strategies in Predicting the Academic Motivation of Male Students of Farhangian University of Yazd. Quarterly Journal of Research in Virtual and School Learning, 2, 28-42. 
Billstein, R., Libeskind, S., \& Lott, J. (2015). A Problem Solving Approach to Mathematics for Elementary School Teachers. Pearson.

Cook, D. B., Casillas, A., Robbins, S. B., \& Dougherty, L. M. (2005). Goal Continuity and the "Big Five" as Predictors of Older Adult Marital Adjustment. Personality and Individual Differences, 38, 519-531. https://doi.org/10.1016/j.paid.2004.05.006

Corno, L., \& Anderman, E. M. (Eds.) (2015). Handbook of Educational Psychology. New York: Routledge.

Dadvand, S. (2013). The Mediating Role of Self-Regulation in the Relationship between Goal Orientation and Educational Achievement in Female Students of Third Year of High School. Master's Thesis, Marvdasht: Islamic Azad University of Marvdasht.

Delavar, A., Esmaeili, N., Hassanvandi, S., \& Hassanvand, B. (2015). Investigation of the Relationship of Self-Regulation Learning Strategies and Different Kinds of Orientation to Students' Educational Achievement. Quarterly Journal of Educational Psychology, 11, 58-75.

Elliot, A. J., \& McGregor, H. A. (2001). A $2 \times 2$ Achievement Goal Framework. Journal of Personality and Social Psychology, 80, 501-519.

https://doi.org/10.1037/0022-3514.80.3.501

Elliot, A. J., McGregor, H. A., \& Gable, S. (1999). Achievement Goals, Study Strategies, and Exam Performance: A Mediational Analysis. Journal of Educational Psychology, 91, 549-563. https://doi.org/10.1037/0022-0663.91.3.549

Farahani, M., \& Keramati, E. (2002). Investigating the Relationship between Self-Efficacy with Attitude and Academic Performance of Math Lessons in Secondary School Students in Tehran. Quarterly Journal of Humanities, Alzahra University, 12, 107-123.

Fouladchang, M. (2007). Investigating the Effect of Metacognitive Processing on Problem Solving. Journal of Social and Human Sciences, University of Shiraz, 26, 95-109.

Khakbaz, A. S., \& Mousspour, N. (2008). Taking Profit from Informal Mathematics to Design Learning Opportunities in Mathematical Curriculum. Quarterly Journal of Curriculum Studies, 4, 28-38.

Kiliç-Çakmak, E. (2010). Learning Strategies and Motivational Factors Predicting Information Literacy Self-Efficacy of e-Learners. Australasian Journal of Educational Technology, 26, No. 2. https://doi.org/10.14742/ajet.1090

Kuhn, D. (2006). Do Cognitive Changes Accompany Developments in the Adolescent Brain? Perspectives on Psychological Science, 1, 59-67.

https://doi.org/10.1111/j.1745-6924.2006.t01-2-.x

Liem, A. D., Lau, S., \& Nie, Y. (2008). The Role of Self-Efficacy, Task Value, and Achievement Goals in Predicting Learning Strategies, Task Disengagement, Peer Relationship, and Achievement Outcome. Contemporary Educational Psychology, 33, 486-512. https://doi.org/10.1016/j.cedpsych.2007.08.001

Marchis, I. (2011). Factors That Influence Secondary School Students' Attitude to Mathematics. Procedia-Social and Behavioral Sciences, 29, 786-793.

https://doi.org/10.1016/j.sbspro.2011.11.306

Martinez, M. E. (2006). What Is Metacognition? Phi delta kappan, 87, 696-699. https://doi.org/10.1177/003172170608700916

McCormick, C. B., Dimmitt, C. A. R. E. Y., \& Sullivan, F. R. (2013). Metacognition, Learning, and Instruction. Handbook of Psychology, 7, 69-97.

Midgley, C. (2014). Goals, Goal Structures, and Patterns of Adaptive Learning. Routledge.

Miller, T. M., \& Geraci, L. (2011). Training Metacognition in the Classroom: The Influence of Incentives and Feedback on Exam Predictions. Metacognition and Learning, 6, 
303-314. https://doi.org/10.1007/s11409-011-9083-7

Montague, M., Warger, C., \& Morgan, T. H. (2000). Solve It! Strategy Instruction to Improve Mathematical Problem Solving. Learning Disabilities Research \& Practice, 15, 110-116. https://doi.org/10.1207/SLDRP1502_7

Moshtaghi, S. (2012). Predicting Educational Progress on the Basis of Goal Progression Orientation. Quarterly Journal of Educational Strategies, 5, 89-94.

Pintrich, P. R., \& De Groot, E. V. (1990). Motivational and Self-Regulated Learning Components of Classroom Academic Performance. Journal of Educational Psychology, 82, 33-40. https://doi.org/10.1037/0022-0663.82.1.33

Price, C. S. (2016). Connecting Metacognition and Mathematical Proficiency: A Case Study of South African Matriculants. Doctoral Dissertation.

Rabab'h, B. S. H. (2015). Mathematics Learning Strategy and Mathematics Achievement among Middle School Students in North of Jordan. Doctoral Dissertation, Kedah: Universiti Utara Malaysia.

Rabbani, Z., \& Youssefi, F. (2014). The Relationship between Motivational Beliefs and Educational Progress with the Mediating Role of Different Kinds of Goal Orientation and Self-Regulation Learning Strategies. Journal of Psychology, 18, 247-262.

Razavieh, A., Seif, D., \& Taheri, A. (2005). Investigating the Effect of Anxiety Components and Attitude towards Mathematics on Educational Achievement of Secondary School Students in the Lesson of Mathematics. Shiraz: Shiraz University.

Rostami, F., \& Aliabadi, V. (2014). The Impact of Cognitive and Metacognitive Learning Strategies in Predicting the Motivation of Academic Achievement in the Students of Agriculture. Quarterly Journal of Research on Agricultural Education Management, 6, 67-76.

Tsai, J. L., Miao, F. F., Seppala, E., Fung, H. H., \& Yeung, D. Y. (2007). Influence and Adjustment Goals: Sources of Cultural Differences in Ideal Affect. Journal of Personality and Social Psychology, 92, 1102-1117. https://doi.org/10.1037/0022-3514.92.6.1102

Vollrath, M., Banholzer, E., Caviezel, C., Fischli, C., \& Jungo, D. (1994). Coping as a Mediator or Moderator of Personality in Mental Health. Personality Psychology in Europe, 5, 262-273.

Weissi, K., \& Talepassand, S. (2014). The Relationship of Goal Progression Orientation, Perceived Structures of Classroom and Cognitive and Metacognitive Strategies to Progress in Mathematics. Cognitive Strategies in Learning, 1, 67-81.

Wigfield, A., \& Cambria, J. (2010). Students' Achievement Values, Goal Orientations, and Interest: Definitions, Development, and Relations to Achievement Outcomes. Developmental Review, 30, 1-35. https://doi.org/10.1016/j.dr.2009.12.001

Wrosch, C., Amir, E., \& Miller, G. E. (2011). Goal Adjustment Capacities, Coping, and Subjective Well-Being: The Sample Case of Caregiving for a Family Member with Mental Illness. Journal of Personality and Social Psychology, 100, 934-946. https://doi.org/10.1037/a0022873

Yar Mohammadi Vassel, M., Rashid, K., \& Bahrami, F. (2014). The Effect of Learning through Playing on the Improvement of the Attitude towards Mathematics in Female Elementary School Students. Quarterly Journal of School Psychology, 3, 122-135.

Zaki, M. A. (2011). Attitude of Students towards Mathematics and Its Relationship with Exam Anxiety (Case Study: Male and Female Students of the Second Year of High Schools in the City of Isfahan). Psychological Studies, 7, 153-181. 